\title{
Maxillofacial fractures surgically treated: a 3-year experience of a Cuban hospital
}

\author{
Fracturas maxilofaciales tratadas quirúrgicamente: experiencia de 3 años de un hospital \\ cubano
}

\author{
Ibraín E. Corrales-Reyes ${ }^{*}$, Alain Manuel Chaple-Gil2,3, Denia Morales-Navarro4, \\ Yuri A. Castro-Rodríguez, and Christian R. Mejia ${ }^{6}$ \\ 'Department of Maxillofacial Surgery, Medical University of Granma, "Carlos Manuel de Céspedes" General University Hospital, Bayamo, Cuba; \\ ${ }^{2}$ Faculty of Medicine, Medical University of La Habana, Victoria de Girón, La Habana, Cuba; ${ }^{3}$ Department of Dentistry, La Pradera International \\ Health Care Center, La Habana, Cuba; ${ }^{4}$ Faculty of Dentistry, Medical University of La Habana, La Habana, Cuba; ${ }^{5}$ Faculty of Dentistry, San Marcos \\ Major National University, Lima Perú; ${ }^{6}$ School of Medicine, Continental University, Huancayo, Perú
}

\begin{abstract}
Aim: The aim of the study was to characterize the maxillofacial fractures surgically treated in a Cuban hospital. Materials and methods: This was a descriptive and retrospective cross-sectional study based on the medical records of patients attended between January 1, 2017 and December 31, 2019 in the Maxillofacial Surgery Department of Carlos Manuel de Céspedes General University Hospital, Cuba. Age, gender, residency, municipality, etiology, month and year of trauma, number and type of fractures, and alcohol consumption at the time of trauma were recorded. Results: 126 cases and 304 fractures were investigated. Males were the most affected $(n=115 ; 91.27 \%)$. The main etiology was interpersonal violence (IPV) (46.03\%). Seventy-one (56.35\%) patients had zygomatico-maxillary complex fractures. In the multivariate analysis, alcohol consumption was significantly lower as the age increased (aPR: 0.989; confidence interval [Cl] 95\%: 0.979-0.99; $p=0.026$ ), as well as in those patients who lived in urban zones (aPR: 0.57; Cl 95\%: 0.44-0.74; $p<0.001$ ), adjusted by the side of the fracture and the municipality. Conclusions: The profile of the maxillofacial fractures in this Cuban hospital seems to be mixed by age, affecting young people and the elderly. IPV was the major cause of maxillofacial fractures, while zygomatico-maxillary complex bones and mandible were the most affected maxillofacial areas.
\end{abstract}

Key words: Epidemiological studies. Maxillofacial trauma. Emergency department. Facial bones.

\section{Resumen}

Objetivo: Caracterizar las fracturas maxilofaciales tratadas quirúrgicamente en un hospital cubano. Material y Métodos: estudio descriptivo, retrospectivo y transversal basado en las historias clínicas de los pacientes atendidos entre el 1 de enero de 2017 y el 31 de diciembre del 2019 en el departamento de Cirugía Maxilofacial del Hospital General Universitario Carlos Manuel de Céspedes. Las variables estudiadas fueron: edad, sexo, residencia, municipio, etiología, mes y año del trauma, número y tipos de fracturas, y consumo de alcohol. Resultados: Se estudiaron 126 pacientes con 304 fracturas. Los hombres fueron los más afectados $(n=115 ; 91.27 \%$ ). La principal etiología fue la violencia interpersonal (46,03\%). 71 pacientes tuvieron fracturas del complejo cigomático-maxilar. En el análisis multivariado, se encontró que el consumo de alcohol fue menor conforme aumentaba la edad (RPa: 0,989; IC 95\%: 0,979-0,99; $p=0,026$ ), así como en los pacientes que vivían en la zona

\section{Correspondence:}

*Ibraín E. Corrales-Reyes

Ignacio Pérez \# 12A e/Avda. 26 de Julio y Donato Mármol

C.P. 87300 , Jiguaní-Granma, Cuba

Fecha de recepción: 24-08-2020

Fecha de aceptación: 25-10-2020

Cir Cir. 2021;89(6):740-747

E-mail: iecorralesr@infomed.sld.cu

DOI: $10.24875 / C I R U .20000933$

Contents available at PubMed

www.cirugiaycirujanos.com

0009-7411/@ 2020 Academia Mexicana de Cirugía. Published by Permanyer. This is an open access article under the terms of the CC BY-NC-ND license (http://creativecommons.org/licenses/by-nc-nd/4.0/). 
urbana (RPa: 0,57; IC 95\%: 0,44-0,74; $p<0,001$ ); ajustados por el lado de la fractura y el municipio de residencia. Conclusiones: El perfil de las fracturas maxilofaciales en este hospital cubano muestra afectación tanto de jóvenes como adultos. La violencia interpersonal fue la principal etiología de las fracturas y las áreas más afectadas fueron la cigomáticomaxilar y mandibular.

Palabras Clave: Estudios epidemiológicos. Trauma maxilofacial. Departamentos de emergencia. Huesos faciales.

\section{Introduction}

Maxillofacial traumas (MFT) and more specific fractures can be considered as consequential conditions as they may result in mortality, severe morbidity, facial disfigurement, and functional limitations ${ }^{1,2}$. Early diagnosis of MFT is thus essential not only to detect concomitant injuries and emergent complications, but also to plan the reconstruction of functional areas.

The epidemiology of MFT varies between populations, it costumes and other demographics matters ${ }^{1,3}$. Injuries caused by traffic, domestic, and work accidents are some causes that provoke MFT, and firsts constitute an important public health problem, since they are the eighth cause of death in the world, especially in the young population between 15 and 29 years of age ${ }^{2,4}$. Further, MFT are among the most common cause of presentations in an emergency department ${ }^{1}$.

MFT can affect the patient's ability to eat, speak, and interact ${ }^{5}$ hence the importance, once the trauma has occurred, to restore the patient's normal functions in a timely and adequate manner. However, to achieve this, it is important to know how these traumas are specifically developed in the regions and localities where the appropriate services are provided to treat these ailments.

The patterns of MFT have been studied in different countries, such as Colombia ${ }^{2}$, Brazil ${ }^{3,6}$, Chile$^{7}$, Chi$\mathrm{na}^{8,9}$, United States ${ }^{10}$, Ethiopia ${ }^{11}$, India ${ }^{12-15}$, Iran ${ }^{16}$, Mexico $^{17}$, Malaysia ${ }^{18}$, Nigeria ${ }^{19}$, United Kingdom ${ }^{20}$, Sudan $^{21}$, and Romania ${ }^{22}$. However, few published Cuban articles are available analyzing the epidemiology and management of MF fractures in general ${ }^{23-26}$. This fact enhances the importance of this research.

Maxillofacial injury poses a challenge to oral and maxillofacial surgeons working in developing countries with limited resource and human power ${ }^{11}$. Maxillofacial treatment depends on the pattern and severity of the trauma and may be conservatively with debridement and suture, closed reduction with arch bar or eyelets, or surgically with open reduction using titanium mini plates. Procedures with open reduction resulted satisfactory facial esthetic, shortened duration of work absence, and preserves function early and reduced the incidence of complications ${ }^{13}$. Due to anteriorly raised, this article aims to characterize the maxillofacial fractures surgically treated in a Cuban hospital.

\section{Materials and methods}

The present study involved a 3-year descriptive, and retrospective cross-sectional study in patients with maxillofacial fractures who were surgically treated (open surgical treatment or open reduction and internal fixation) in the Maxillofacial Surgery Department of Carlos Manuel de Céspedes General University Hospital, Bayamo, Granma, Cuba. This hospital is responsible for the secondary care of patients from the capital and other six municipalities of the Granma Province. However, patients from other municipalities with neurosurgical issues are attended too because the unique Neurosurgery Department of the province is located at this hospital. The time period was from January 1, 2017 to December 31, 2019.

The study inclusion criteria were: (a) patients of both sexes and all age groups; (b) a history of an acute trauma episode; (c) X-ray or computed tomography confirming the clinical diagnosis of fracture and evidencing its location and characteristics (with or without contiguous bodily fractures/injuries); (d) surgical treatment of the fracture performed in the study host institution; and (e) signing of an informed consent by all patients, through which they agreed to the use of their medical data for scientific research. Patients with incomplete medical records or with unclear data were excluded from the study. During these 3 years, 132 patients with maxillofacial fractures were treated in our department. However, six cases had unclear/incomplete record and were excluded from the study.

Data were collected by the principal investigator using predesigned templates. The data collected from the patient's record were: age, gender, residency (urban/rural), municipality, etiology, month and year of trauma, number of fractures, the topographic location of the fracture (zygomatico-maxillary complex, mandible, Le Fort I, Le Fort II, Le Fort III, pan facial, orbital 
Table 1. Distribution of patients according to socio-demographic characteristics

\begin{tabular}{|c|c|c|c|c|c|c|c|c|c|}
\hline \multirow[t]{3}{*}{ Socio-demographic characteristics } & \multirow{2}{*}{\multicolumn{2}{|c|}{ Patients }} & \multicolumn{4}{|c|}{ Gender } & \multirow{2}{*}{\multicolumn{2}{|c|}{ Fractures }} & \multirow[t]{3}{*}{ Ratio fracture: patient } \\
\hline & & & \multicolumn{2}{|c|}{ Male } & \multicolumn{2}{|c|}{ Female } & & & \\
\hline & $\mathbf{n}$ & $\% *$ & $\mathrm{n}$ & $\%$ & $\mathrm{n}$ & $\%$ & $\mathbf{n}$ & $\%{ }^{\star *}$ & \\
\hline \multicolumn{10}{|l|}{ Age groups } \\
\hline$\leq 20$ & 11 & 8.73 & 11 & 100 & 0 & - & 26 & 8.55 & 2.36 \\
\hline $21-40$ & 52 & 41.27 & 46 & 88.46 & 6 & 11.54 & 119 & 39.14 & 2.29 \\
\hline $41-60$ & 52 & 41.27 & 49 & 94.23 & 3 & 5.77 & 129 & 42.43 & 2.48 \\
\hline$\geq 61$ & 11 & 8.73 & 9 & 81.82 & 2 & 18.18 & 30 & 9.87 & 2.73 \\
\hline \multicolumn{10}{|l|}{ Residency } \\
\hline Rural & 61 & 48.41 & 56 & 91.80 & 5 & 8.20 & 149 & 49.01 & 2.44 \\
\hline Urban & 65 & 51.59 & 59 & 90.77 & 6 & 9.23 & 155 & 50.99 & 2.54 \\
\hline \multicolumn{10}{|l|}{ Fractures per patient } \\
\hline 1 & 24 & 19.05 & 20 & 83.33 & 4 & 16.67 & 24 & 7.89 & 1.00 \\
\hline 2 & 50 & 39.68 & 48 & 96.00 & 2 & 4.00 & 100 & 32.89 & 2.00 \\
\hline 3 & 35 & 27.78 & 32 & 91.43 & 3 & 8.57 & 105 & 34.54 & 3.00 \\
\hline 4 & 13 & 10.32 & 11 & 84.62 & 2 & 15.38 & 52 & 17.11 & 4.00 \\
\hline$\geq 5$ & 4 & 3.17 & 4 & 100 & 0 & - & 23 & 7.57 & 5.75 \\
\hline \multicolumn{10}{|l|}{ Years } \\
\hline 2017 & 42 & 33.33 & 37 & 88.06 & 5 & 14.29 & 92 & 30.26 & 2.19 \\
\hline 2018 & 34 & 26.98 & 34 & 100 & 0 & - & 83 & 27.30 & 2.44 \\
\hline 2019 & 50 & 39.68 & 44 & 88.00 & 6 & 12.00 & 129 & 42.43 & 2.58 \\
\hline Total & 126 & 100 & 115 & 91.27 & 11 & 8.73 & 304 & 100 & 2.41 \\
\hline
\end{tabular}

floor, and naso-orbito-etmoidal), and alcohol consumption at the time of trauma (yes/no). The etiology of trauma was divided into five main categories: (a) interpersonal violence (IPV); (b) animal attacks; (c) accidents, which include road traffic, sport, bike and job; (d) fall; and (e) complicated extractions. The patients' age ranged from 13 to 84 years, and they were divided into four age groups: younger than 20 years, 21 to 40,41 to 60 , and older than 61 years. Alcohol consumption information collected was based on medical record. Mandibular fractures included fractures of the symphysis, parasymphysis, body, angle, ramus, coronoid, and condyle.

This research is in accordance with all ethical standards. The Scientific Ethics Committee of the hospital approved the project. The ethical committee also provided permission to review the medical records of the patients.

Descriptive statistics was performed with a two decimal percentage accuracy. Continuous data were expressed as mean and standard deviation, and nominal data were expressed as frequency and percentage. The raw (bivariate) and adjusted (multivariate) associations according to alcohol consumption were calculated. To obtain raw and adjusted prevalence ratio, generalized linear models, with the use of the Poisson family, log linkage function, and thick models, were constructed and adjusted by setting municipalities as a cluster group. The statistical analysis was elaborated in Stata version 11.1 (StataCorp LP, College Station, TX, USA), and $p \leq 0.05$ was considered statistically significant.

\section{Results}

As shown in table 1, in 126 patients treated surgically, 304 maxillofacial fractures were found (approximately two fractures per patient). A greater proportion of injured patients were males (115) compared with females (11) resulting in a ratio of $10.45: 1$. The age of patients at the time of injury ranged from 13 to 84 years, with a mean age of $39.99( \pm 14.62)$ years. The commonest age groups were 21-40 and 41-60 reporting 52 cases $(41.27 \%)$, respectively. When disaggregated by residency, the highest frequency was observed in male urban patients $(90.77 \%)$.

The distribution of the patients according to municipalities is the following: Bayamo $(n=59)$, Jiguaní ( $n$ $=15)$, Guisa $(n=13)$, Buey Arriba $(n=13)$, Cauto Cristo $(n=10)$, Río Cauto $(n=9)$, Manzanillo $(n=4)$, Campechuela $(n=1)$, Bartolomé Masó $(n=1)$, and Yara $(n=1)$. As shown in table 2, alcohol consumption 
Table 2. Association between alcohol consumption and maxillofacial fractures incidence

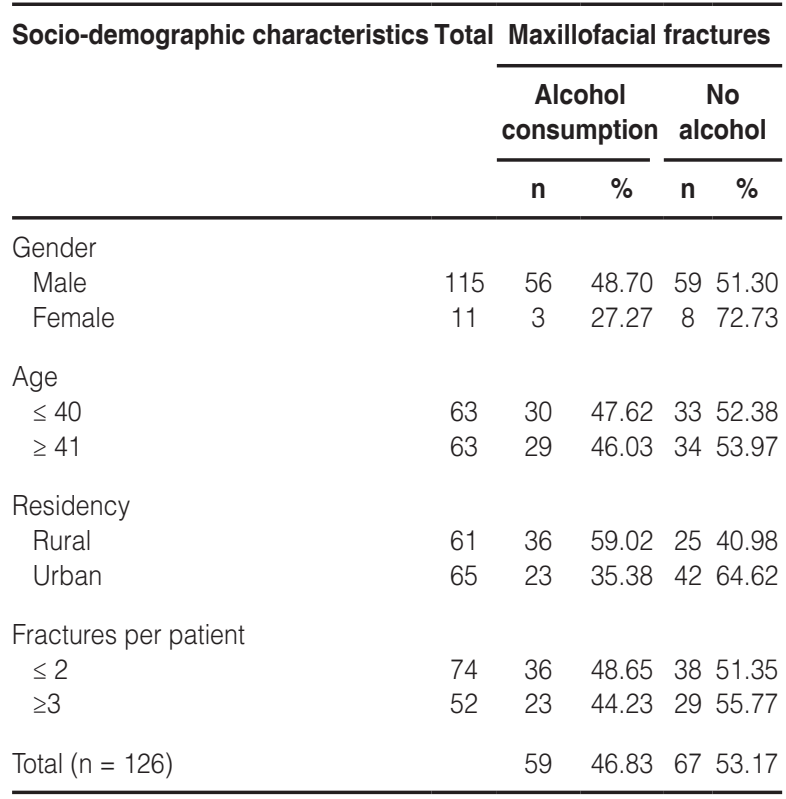

was recorded in $46.83 \%$ of the patients, mainly in males $(n=56)$, as well as those aged $\leq 40$ years ( $n$ $=30$ ). In 36 rural patient alcohol consumption before the incidence of the trauma was recorded.

In the bivaried analysis, alcohol consumption was significantly lower as the age increased $(p=0.047)$, in urban patients $(p=0.001)$, and it was higher in the left side fractures $(p=0.042)$. In the multivariate analysis, taking into consideration this three variable of the bivariate associations, alcohol consumption was significantly lower as the age increased (aPR: 0.989; confidence interval [Cl] 95\%: 0.979-0.99; $p=0.026$ ), as well as in those patients who lived in urban zones (aPR: 0.57; Cl 95\%: 0.44-0.74; $\mathrm{p}<0.001$ ), adjusted by the side of the fracture and the municipality.

IPV was found to be the paramount etiological factor for maxillofacial fractures $(46.03 \%)$, followed by road traffic accident (RTA) (17.46\%). Animals attacks, bikerelated accidents, and falls had equal contribution (n $=12 ; 9.52 \%$, respectively). Patients aged $\leq 40$ years were mainly affected by IPV ( $n=32 ; 50.79 \%)$. RTArelated fractures were commonest in male patients ( $n$ $=21 ; 18.26 \%$ ) as well as in those aged $\geq 41$ years ( $n$ $=15 ; 23.81 \%$ ). In rural patients, $54.10 \%$ and $13.11 \%$ cases were due to IPV and animal attacks, respectively. Only two maxillofacial fractures (mandibular angle) were due to complicated teeth extractions (Table 3).

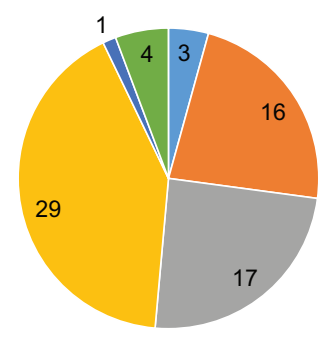

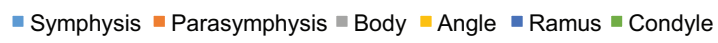

Figure 1. Anatomical locations of mandibular fractures.

As shown in table 4, the most common etiology was IPV, followed by RTA, both mainly related with zygomatico-maxillary complex fractures reporting 31 and 13 patients, respectively. Among patterns of mandibular fractures (51 cases), in 28 patients the etiology was IPV (54.90\%). Le Fort I pattern was seen in six cases related with IPV and RTA.

The mandibular fracture pattern showed that isolated fractures were most common $(n=49,96.08 \%)$. Three patients had mandibular fractures combined with zygomatico-maxillary complex fractures. Mandibular fractures of the right side were more common $(n=21,41.18 \%)$ than bilateral $(n=16,31.37 \%)$. Left fractures ( $n=14,27.45 \%$ ) were least common. As shown in figure 1 , the anatomical distribution is the following: angle $(n=29)$, body $(n=17)$, parasymphysis $(n=16)$, condyle $(n=4)$, symphysis $(n=3)$, and ramus $(n=1)$.

The detail by year and months is presented in figure 2. There were 42 (33.33\%) hospital admissions in 2017, 34 (26.98\%) in 2018 and 50 (39.68\%) in 2019. In this last year, a peak in incidence was noted in January, $2019(n=7)$.

\section{Discussion}

Maxillofacial fractures affect the individual not only by limiting the functional aspect, but also hampering the esthetics. MFT needs special attention due to their close proximity to and frequent involvement of vital organs, and for this reason, thorough evaluation of the maxillofacial region is mandatory during the primary stages of trauma care ${ }^{12}$. In this study, we only included patients treated surgically to obtain an epidemiological profile of the severe MFT in this Cuban hospital.

Trends and characteristics of maxillofacial injuries vary from one population to another depending on 
Table 3. Etiology of maxillofacial fractures in relation to socio-demographic variables

\begin{tabular}{|c|c|c|c|c|c|c|c|c|}
\hline \multirow[t]{3}{*}{ Variables } & \multicolumn{8}{|c|}{ Etiology n (\%) } \\
\hline & \multirow{2}{*}{\multicolumn{2}{|c|}{ Interpersonal violence Animal attacks }} & \multicolumn{4}{|c|}{ Accidents } & \multirow[t]{2}{*}{ Falls } & \multirow[t]{2}{*}{ Complicated extraction } \\
\hline & & & Road traffic & Sport & Job & Bike & & \\
\hline \multicolumn{9}{|l|}{ Gender } \\
\hline Male $(n=115)$ & $52(45.22)$ & $12(10.43)$ & $21(18.26)$ & $5(4.35)$ & $3(2.61)$ & $11(9.57)$ & $9(7.83)$ & $2(1.74)$ \\
\hline Female $(n=11)$ & $6(54.55)$ & - & $1(9.09)$ & - & - & $1(9.09)$ & $3(27.27)$ & - \\
\hline \multicolumn{9}{|l|}{ Age } \\
\hline$\leq 40(n=63)$ & $32(50.79)$ & $7(11.11)$ & $7(11.11)$ & $5(7.94)$ & $2(3.17)$ & $6(9.52)$ & $4(6.35)$ & - \\
\hline$\geq 41(n=63)$ & $26(41.27)$ & $5(7.94)$ & $15(23.81)$ & - & $1(1.59)$ & $6(9.52)$ & $8(12.70)$ & $2(3.17)$ \\
\hline \multicolumn{9}{|l|}{ Residency } \\
\hline \multirow{3}{*}{$\begin{array}{l}\text { Rural }(n=61) \\
\text { Urban }(n=65)\end{array}$} & & & & & & & & - \\
\hline & $33(54.10)$ & $8(13.11)$ & $7(11.48)$ & $1(1.64)$ & - & $\mathrm{b}(9.84)$ & $6(9.84)$ & - \\
\hline & $25(38.46)$ & $4(6.15)$ & $15(23.08)$ & $4(6.15)$ & $3(4.62)$ & $6(9.23)$ & $6(9.23)$ & $2(3.08)$ \\
\hline \multicolumn{9}{|l|}{ Number of fractures per } \\
\hline patient & 38 (51.35) & $7(9.46)$ & $8(10.81)$ & $2(2.70)$ & $3(4.05)$ & $7(9.46)$ & $7(9.46)$ & $2(2.70)$ \\
\hline$\leq 2(n=74)$ & $20(38.46)$ & $5(9.62)$ & $14(26.92)$ & $3(5.77)$ & - & $5(9.62)$ & $5(9.62)$ & - \\
\hline$\geq 3(n=52)$ & & & & & & & & \\
\hline \multicolumn{9}{|l|}{ Years } \\
\hline $2017(n=42)$ & $17(40.48)$ & $4(9.52)$ & $7(16.67)$ & $3(7.14)$ & $1(2.38)$ & $6(14.29)$ & $2(4.76)$ & $2(4.76)$ \\
\hline $2018(n=34)$ & $16(47.06)$ & $3(8.82)$ & $8(23.53)$ & $2(5.88)$ & $2(5.88)$ & $2(5.88)$ & $1(2.94)$ & - \\
\hline $2019(n=50)$ & $25(50.00)$ & $5(10.00)$ & $7(14.00)$ & - & - & $4(8.00)$ & $9(18.00)$ & - \\
\hline Total patients $(n=126)$ & $58(46.03)$ & $12(9.52)$ & $22(17.46)$ & $5(3.97)$ & $3(2.38)$ & $12(9.52)$ & $12(9.52)$ & $2(1.59)$ \\
\hline
\end{tabular}

Table 4. Distribution of maxillofacial fractures according to etiology

\begin{tabular}{|c|c|c|c|c|c|c|c|c|c|}
\hline \multirow{3}{*}{$\begin{array}{l}\text { Maxillofacial } \\
\text { fractures }\end{array}$} & \multirow[t]{3}{*}{ Patients } & \multicolumn{8}{|c|}{ Etiology n (\%) } \\
\hline & & \multirow{2}{*}{\multicolumn{2}{|c|}{$\begin{array}{l}\text { Interpersonal Animal attacks } \\
\text { violence }\end{array}$}} & \multicolumn{4}{|c|}{ Accidents } & \multirow[t]{2}{*}{ Falls } & \multirow[t]{2}{*}{ Complicated extractior } \\
\hline & & & & Road traffic & Sport & Job & Bike & & \\
\hline $\begin{array}{l}\text { Zygomatico-Maxillary } \\
\text { Complex }\end{array}$ & 71 & $31(43.66)$ & $7(9.86)$ & $13(18.31)$ & $4(5.63)$ & $3(4.23)$ & $7(9.86)$ & $6(8.45)$ & - \\
\hline Mandibular & 51 & $28(54.90)$ & $3(5.88)$ & $8(15.69)$ & $1(1.96)$ & - & $4(7.84)$ & $5(9.80)$ & $2(3.92)$ \\
\hline Le Fort I & 6 & $2(33.33)$ & $1(16.67)$ & $2(33.33)$ & & - & $1(16.67)$ & - & - \\
\hline Pan facial & 3 & - & $1(33.33)$ & $2(66.67)$ & - & - & - & - & - \\
\hline Orbital floor & 2 & $1(50.00)$ & - & $1(50.00)$ & - & - & - & - & - \\
\hline Naso-Orbito-Etmoidal & 1 & $1(100)$ & - & - & - & - & - & - & - \\
\hline Le Fort II & 1 & $1(100)$ & - & - & - & - & - & - & - \\
\hline Le Fort III & 1 & - & - & $1(100)$ & - & - & - & - & - \\
\hline
\end{tabular}

certain peculiarities such as socioeconomic, cultural, and environmental factors ${ }^{19}$. In our study, the sex distribution of maxillofacial fractures incidence is highly frequent in males. The overall male to female ratio was 10.45:1. Our finding was higher than to several previously conducted studies in Brazil (4.63:1) ${ }^{6}$, Chile
$(1.7: 1)^{7}$, Ethiopia $(4.02: 1)^{11}$, India $(3.3: 1 \text { and 2.9:1) })^{12,15}$, Iran $(4.07: 1)^{16}$, Nigeria $(3.4: 1)^{19}$, Sudan $(2.2: 1)^{21}$, and Cuba $\left(2.7: 1,2.19: 1\right.$, and 4.1:1) ${ }^{24-26}$. These results might be due to that men tend to be more often involved in aggressive and conflict-ridden situations and are mostly involved in outdoor activities than women. 


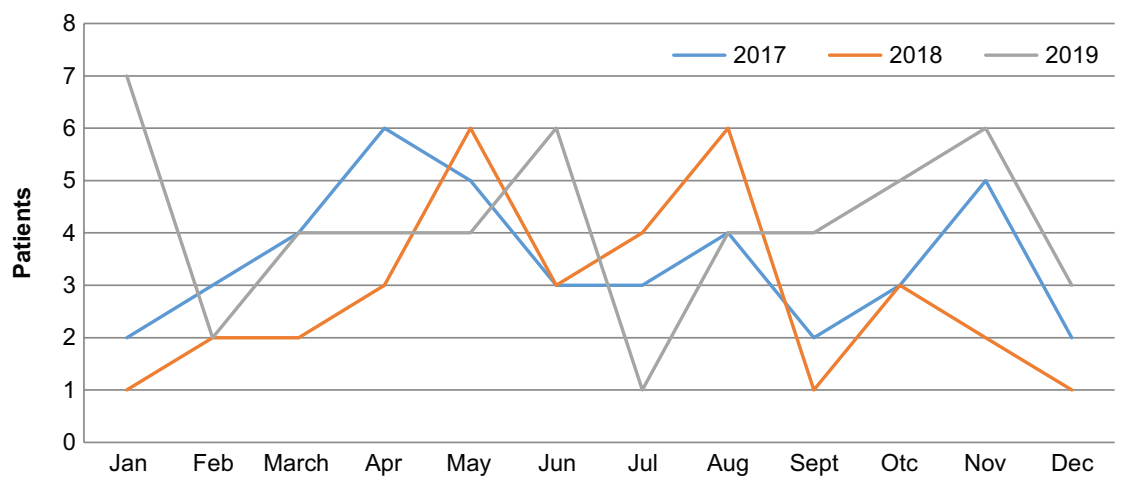

Figure 2. Annual and monthly distribution of patients with maxillofacial fractures.

Lesser incidence of maxillofacial fractures in females could be because of lesser reporting of injuries - due to either the sex-based neglect still prevalent in many rural areas or domestic abuse ${ }^{14}$.

With regard to the age, our study showed same number of patients in the 21-40 and 41-60 age groups. We believe this finding maybe associated with the fact that patients of this age represent a group with intense social interaction, participate in dangerous exercises and sports, drive motor vehicles without safety measures, and are more involved in situations of IPV, making them the most susceptible group ${ }^{6}$.

Esses et al. in Brazil ${ }^{6}$, Werlinger et al. in $\mathrm{Chile}^{7}$, Teshome et al. in Ethiopia ${ }^{11}$, Agarwal et al. in India ${ }^{14}$, Samieirad et al. in $\operatorname{Iran}^{16}$, Shoraourddi et al. in Malay$\mathrm{sia}^{18}$, and Morales et al. in $\mathrm{Cuba}^{24-26}$ reported a high incidence of trauma in young adults in their third decades. Pediatric fractures ( $\leq 20$ years old patients) accounted for $8.73 \%$ in our study, which is consistent with literature ${ }^{14,15}$. In agreement with these previous studies ${ }^{14,15}$, we did not observe facial fractures before 10 years of age, while their incidence progressively increases with the beginning of school and adolescence. This has been widely reported in the scientific literature that directly associates the lifestyles of the youngest with risk behaviors that increase the probability of suffering intentional or unintentional injuries? ${ }^{7}$.

Trauma has been considered the leading cause of death in individuals aged 1-44 years and the main cause of lost productivity in a specific population ${ }^{6,27}$. This information highlights the importance of identifying risk factors and use of preventive measures for injuries, as it would reduce the number of deaths, as well as disability or withdrawal from work or student activities, due to trauma ${ }^{28}$. At present, the association of alcohol, drugs, vehicle management, and urban violence increase is increasingly present in the etiology of facial trauma, even increasing its complexity. Thus, there is a need to know the cause, severity, and time distribution to set priorities for effective treatment and prevention of these injuries, which is related to the identification of possible direct or indirect risk factors for MFT ${ }^{6}$.

There is a stark difference between the incidence and etiology of trauma in developed and developing countries. In American, African, and Asian countries, RTAs have been shown to be the predominant cause $^{29,30}$. The present study revealed that IPV $(46.03 \%)$ was the leading cause of maxillofacial fractures. Our results are similar to experiences reported in Chile ${ }^{6}$, Ethiopia ${ }^{11}$, and in France ${ }^{31}$. In contrast, RTArelated factures were the most common in several studies $^{6,12-16,18,19,21,24-26}$.

This study revealed a $46.83 \%$ of alcoholic ingestion before the trauma. In the multivariate analysis, alcohol consumption was significantly lower as the age increased, as well as in those patients who lived in urban zones. Alcohol involved facial injuries may be more serious than non-alcohol related facial injuries as evident by higher proportion of patients requiring surgery ${ }^{32}$. Facial injuries from alcohol related trauma places a high burden on hospital resources. As alcohol related MFT can be potentially preventable, educational programs and alcohol intervention strategies should be implemented to reduce such health hazards.

In our study, the zygomatico-maxillary complex bones were the most fractured followed by the mandible. These results can be due to these bones prominence in the viscerocranium, which makes it susceptible to trauma. Furthermore, the zygomatic 
complex is biomechanically the lateral weight-bearing pillar of the midface, absorbing a large part of the kinetic energy of the wounding agents ${ }^{19,22}$. Another aspect that should not be neglected is human defense instinct. People are frequently tempted to turn their head at the moment of the trauma, avoiding in this way frontal impact in the middle of the face $^{22,33}$.

In a study published by Farneze et al..$^{34}$ in 2016 that described maxillomandibular trauma of Brazilian patients at a reference center in oral and maxillofacial service, this relation was invested. Our results are in accordance with the earlier study from India by Satpathy et al. $^{12}$ However, they are opposite to previously conducted studies in India ${ }^{13}$, in Iran ${ }^{16}$, in Romania ${ }^{22}$, and in $\mathrm{Cuba}^{25,26}$ where the mandible was the most fractured facial bone.

The majority of the patients in this study had two lines of fractures (39.68\%). Contrary to our results, others authors reported a prevalence of patients with a single fracture trajectory ${ }^{22}$. The mentioned differences can be explained by the fact that the patterns of craniofacial fractures depends on a multitude of factors such as the type, direction, kinetic energy of the injuring agent or the position of the head at the time of the trauma, and especially on the fracture mechanism, leading to many possible variants of association of the fracture foci ${ }^{33}$.

Our study provide useful knowledge about the current distribution of facial fractures in our hospital, as well as offering a new valuable health-care system database that might improve medical and dental policies to prevent and manage facial trauma. Limitations of the study are that being retrospective; it may be subject to information bias due to inaccurate initial examination and incomplete or incorrect documentation. To minimize this shortcoming, only full medical records were selected.

\section{Conclusions}

The majority of the patients in the present study were male, rural, with admission in 2019. IPV remains the major cause of maxillofacial fractures and the young adult males were the main victims in the studied sample. Alcohol involvement is frequent in facial fracture presentations. The most frequent fractures are zygomatic-maxillary complex fractures. The fractures located in mandibular angle were the most frequent in this bone.

\section{Conflict of Interest}

The authors declare that there is no conflict of interest.

\section{Ethics approval}

The Scientific Ethics Committee of the Carlos Manuel de Céspedes General University Hospital approved the project.

\section{Ethical disclosures}

Protection of human and animal subjects. The authors declare that no experiments were performed on humans or animals for this study.

Confidentiality of data. The authors declare that no patient data appear in this article.

Right to privacy and informed consent. The authors declare that no patient data appear in this article.

\section{References}

1. Abosadegh MM, Saddki N, Al-Tayar B, Rahman SA. Epidemiology of maxillofacial fractures at a teaching hospital in Malaysia: a retrospective study. Biomed Res Int. 2019;2019:e9024763.

2. Da Rosa A, Granke G, Faot F, Rezende L, Manzolli F, Torriani M. Etiology, diagnosis, and demographic analysis of maxillofacial trauma in elderly persons: a 10-year investigation. J Craniomaxillofac Surg. 2017;45:1921-26.

3. Domingues L, Da Silveira A, Giacomelli G, Guerra R, Henrique R, Manzolli F. Epidemiology and risk factors of maxillofacial injuries in Brazil, a 5-year retrospective study. J Maxillofac Oral Surg. 2018;17:169-74.

4. Chuang KT, Hsieh F, Liao HT. The correlation of age and patterns of maxillofacial bone fractures and severity of associated injuries caused by motorcycle accidents. Ann Plast Surg. 2019;83:e28-34.

5. Marques L, De Macedo I, Nóbrega K, Lira J, Targino A, D'Avila S. Pattern of oral-maxillofacial trauma from violence against women and its associated factors. Dent Traumatol. 2017;33:181-8.

6. Esses DF, Costa FW, Sá CD, Silva PG, Bezerra TM, Carvalho FS, et al. Occupational group, educational level, marital status and deleterious habits among individuals with maxillofacial fractures: retrospective study. Med Oral Patol Oral Cir Bucal. 2018;23:e13-22.

7. Werlinger F, Villalón M, Duarte V, Acevedo R, Aguilera R, Alcocer D, et al. Trends of maxillofacial trauma: an update from the prospective register of a multicenter study in emergency services of Chile. Med Oral Patol Oral Cir Bucal. 2019;24:e588-94.

8. Zhou H, Lv K, Yang R, Li Z, Li Z. Mechanics in the production of mandibular fractures: a clinical, retrospective case-control study. PLoS One. 2016;11:e0149553.

9. Yu W, Chen H, Lv Y, Deng Q, Kang P, Zhang L. Comparison of influencing factors on outcomes of single and multiple road traffic injuries: a regional study in Shanghai, China (2011-2014). PLoS One. 2017;12:e0176907.

10. Cillo JE, Homes TM. Interpersonal violence is associated with increased severity of geriatric facial trauma. J Oral Maxillofac Surg. 2016;74:1023.e1-7.

11. Teshome A, Andualem G, Tsegie R, Seifu S. Two years retrospective study of maxillofacial trauma at a tertiary center in North West Ethiopia. BMC Res Notes. 2017;10:373.

12. Satpathy M, Gupta MK, Kumar A, Prabhu S, Tiwari S, Jain N. Maxillofacial fractures in Bhopal, India: analytic study of 1268 cases. J Maxillofac Oral Surg. 2016:15:25-31.

13. Manodh P, Shankar P, Pradeep D, Santhosh R, Murugan A. Incidence and patterns of maxillofacial trauma-a retrospective analysis of 3611 patients-an update. Oral Maxillofac Surg. 2016;20:377-83.

14. Agarwal P, Mehrotra D, Agarwal R, Kumar S, Pandey R. Patterns of maxillofacial fractures in Uttar Pradesh, India. Craniomaxillofac Trauma Reconst. 2017;10:48-55. 


\section{I.E. Corrales-Reyes, et al.: Maxillofacial fractures surgically treated}

15. Malik S, Singh G, Kaur G, Yadav S, Mittal HC. Orofacial trauma in rural India: a clinical study. Chin J Traumatol. 2017;20:216-21.

16. Samieirad S, Aboutorabzade MR, Tohidi E, Shaban B, Khalife H, Hashemipour MA, et al. Maxillofacial fracture epidemiology and treatment plans in the Northeast of Iran: a retrospective study. Med Oral Patol Oral Cir Bucal. 2017;22:e616-24.

17. Dávila Cervantes CA, Pardo Montaño AM. Analysis of the trend and impact of mortality due to external causes: Mexico, 2000-2013. Salud Colect. 2016;12:251-64.

18. Shoraourddi HS, Rahman SA, Wan M, Liszen T, Shaari R. Correlation among the fractured facial bones in a teaching hospital in Malaysia: a retrospective study of recent 5-years. J Oral Maxillofac Surg Med Pathol. 2020;32:14-8

19. Obimakinde OS, Ogundipe KO, Rabiu TB, Okoje VN. Maxillofacial fractures in a budding teaching hospital: a study of pattern of presentation and care. Pan Afr Med J. 2017;26:218.

20. Bradley D, Leung B, Saxena S, Dungarwalla M, Chapireau D, Fan K. Surgical management of zygomatic complex fractures in a major trauma centre. Plast Aesthet Res. 2019;6:11.

21. Almahdi HA, Higzi MA. Maxillofacial fractures among Sudanese children at Khartoum dental teaching hospital. BMC Res Notes. 2016;9:120.

22. Tent PA, Juncar RI, Juncar M. Clinical patterns and characteristics of midfacial fractures in western romanian population: a 10-year retrospective study. Med Oral Patol Oral Cir Bucal. 2019;24:e792-8.

23. Estrada MG. Epidemiología de las fracturas maxilofaciales tratadas quirúrgicamente en el servicio maxilofacial de Bayamo: 5 años de revisión. Multimed. 2017;21:809-18.

24. Morales D, Brugal I. Trauma maxilofacial en el Servicio de urgencias del hospital universitario "General Calixto García". 2016-2017. Rev Haban Cienc Méd. 2018;17:620-9.
25. Morales D, Aguila Y, Grau IB. Comportamiento del trauma maxilofacial grave. Rev Cubana Estomatol. 2018;55:1-10.

26. Morales D, Barreto V, Durañona L, Rodríguez A. Caracterización del trauma maxilofacial grave en dos servicios de urgencia de La Habana, Cuba. Rev Cubana Estomatol. 2020:57:1-13.

27. Fang X, Zeng G, Linnan HW, Jing R, Zhu X, Corso P, et al. The incidence and economic burden of injuries in Jiangxi, China. Public Health. 2016;138:138-45.

28. Gassner R, Tuli T, Hachl O, Rudisch A, Ulmer H. Cranio-maxillofacial trauma: a 10 year review of 9,543 cases with 21,067 injuries. J Craniomaxillofac Surg. 2003;31:51-61.

29. Boffano P, Roccia F, Zavattero E, Dediol E, Uglešic V, Kovačič Ž. European maxillofacial trauma (EURMAT) in children: a multicenter and prospective study. Oral Surg Oral Med Oral Pathol Oral Radiol. 2015;119:99-504.

30. Boffano P, Kommers SC, Karagozoglu KH, Forouzanfar T. Aetiology of maxillofacial fractures: a review of published studies during the last 30 years. Br J Oral Maxillofac Surg. 2014;52:901-6.

31. Pham-Dang N, Barthélémy I, Orliaguet T, Artola A, Mondié JM, Dallel R. Etiology, distribution, treatment modalities and complications of maxillofacial fractures. Med Oral Patol Oral Cir Bucal. 2014;19:261-9.

32. O'Meara C, Witherspoon R, Hapangama N, Hyam DM. Alcohol and interpersonal violence may increase the severity of facial fractures. $\mathrm{Br} \mathrm{J}$ Oral Maxillofac Surg. 2012;50:36-40.

33. Zhang R, Li W, Pei F, He W. Analysis of 126 hospitalized elder maxillofacial trauma victims in central China. Med Oral Patol Oral Cir Bucal. 2015;20:e464-70.

34. Farneze RB, Prosdocimo ML, Nogueira AP, Cavalcante MA, Hespanhol W, Teixeira TF, et al. Study of the causes of facial fractures in a reference center in Rio de Janeiro, Brazil from 2003-2012. Dent Traumatol. 2016:32:507-9. 